\title{
The patient journey to diagnosis and treatment of autoinflammatory diseases
}

\author{
Jonathan S. Hausmann ${ }^{1,2^{*}}$, Kathleen G. Lomax ${ }^{3}$, Ari Shapiro ${ }^{4}$ and Karen Durrant ${ }^{5}$
}

\begin{abstract}
Background: Limited data are available on the experiences of patients with autoinflammatory diseases (AIDs) and their families along the path to diagnosis and treatment. We sought to describe these experiences in patients with AIDs including tumor necrosis factor receptor-associated periodic syndrome (TRAPS), mevalonate kinase deficiency/ hyperimmunoglobulin D syndrome (MKD/HIDS), and familial Mediterranean fever (FMF).

Methods: Ninety-minute, semi-structured qualitative interviews and 5-day written/video diaries were used to gather information on the experiences of patients with AIDs and their families.

Results: Twelve families of patients from the US (TRAPS $[n=4]$, MKD/HIDS $[n=5]$, FMF $[n=5]$ ) participated in this study from August to November 2015. The study included two families with multiple afflicted siblings. Patients' ages ranged from 1 to 28 years. Most parents reported realizing that something was seriously wrong with their child after medical emergencies and/or hospitalizations, which initiated the difficult path to diagnosis. For most, the process included multiple specialist visits, extensive and repeated testing, and many misdiagnoses. Over time, 92\% of parents reported losing confidence in the healthcare system's ability to find an answer to their child's symptoms, while they also struggled with unsupportive school personnel and dismissive friends and relatives. Patients and their parents reported holding on to memories of "what life was like" before the onset of symptoms and mourning their subsequent loss of "normalcy." Even after diagnosis, patients and parents continued to feel uncertain about what to expect in the future.

Conclusions: All families emphasized the need for efficient early diagnosis of AIDs. Initiatives that improve the speed and accuracy of diagnosis, provide more comprehensive patient education, and support patients and families through the illness have the potential to significantly improve the quality of life of patients with AIDs and their families. Healthcare providers should be aware of the impact of the long diagnostic journey on families and work to create an environment of trust and collaboration in the face of a difficult and prolonged diagnostic process.
\end{abstract}

Keywords: Autoinflammatory diseases, Patient journey, Disease experience, Psycho-social dynamics, Parent experience

\section{Background}

Periodic fever syndromes, such as familial Mediterranean fever (FMF), mevalonate kinase deficiency/hyperimmunoglobulin D syndrome (MKD/HIDS), and tumor necrosis factor (TNF) receptor-associated periodic syndrome (TRAPS), are rare autoinflammatory conditions characterized by recurrent fevers and systemic inflammation [1]. These disorders are challenging to diagnose because their symptoms are nonspecific and resemble other infectious and malignant

\footnotetext{
* Correspondence: jonathan.hausmann@childrens.harvard.edu

${ }^{1}$ Boston Children's Hospital, Boston, MA 02115, USA

${ }^{2}$ Beth Israel Deaconess Medical Center, Boston, MA 02215, USA

Full list of author information is available at the end of the article
}

diseases. Although provisional classification criteria have been developed to help clinicians to diagnose these rare syndromes [2], patients often experience delays in diagnosis ranging from months to years, which can lead to additional morbidity [3-6]. To date, the experiences of such patients and their families along the path to diagnosis have been poorly studied. The objective of this study was to define the stages of the patient journey by following the experiences of patients with AIDs and their families over the time through diagnosis and treatment.

(c) The Author(s). 2018 Open Access This article is distributed under the terms of the Creative Commons Attribution 4.0 International License (http://creativecommons.org/licenses/by/4.0/), which permits unrestricted use, distribution, and reproduction in any medium, provided you give appropriate credit to the original author(s) and the source, provide a link to the Creative Commons license, and indicate if changes were made. The Creative Commons Public Domain Dedication waiver (http://creativecommons.org/publicdomain/zero/1.0/) applies to the data made available in this article, unless otherwise stated. 


\section{Methods}

Patients with AIDs and their families were recruited by physicians with expertise in AIDs and through the Autoinflammatory Alliance, an AIDs patient support group. Researchers used qualitative, in-depth, semi-structured telephone interviews (Interview guide is available online as Additional file 1) and 5-day written and video diaries to explore the history and daily lives of these families. This was a market research study and therefore no ethics committee approval was required. All patients provided written informed consent to participate.

\section{Results}

\section{Patient and family characteristics}

Twelve families of patients with autoinflammatory diseases participated in this study from August to November 2015. Families included 4 patients with TRAPS, 5 with MKD/HIDS, and 5 with FMF $(n=5)$; two families had multiple afflicted siblings. Patients' ages ranged from 1 to 28 years and all were from the United States. The time to diagnosis varied from 2.5-24 years; in patients whose siblings or other family members had already been diagnosed, the time to diagnosis was shorter. The age (median [min- max]) at diagnosis was 4 (3-10), 4.5 (1-15) and 3 (2-16) years for TRAPS, FMF and HIDS patients, respectively. Patients were currently receiving or had previously been treated with one or more of the following medications: colchicine, anakinra, canakinumab, tocilizumab, and anti-TNF agents (etanercept, adalimumab, and certolizumab).

\section{Parents' perceptions pre-diagnosis}

Children with AIDs in this study appeared healthy during their early childhood, with most meeting early developmental milestones. Childhood illnesses emerged but rarely raised the alarm for the parents (Fig. 1a). Owing to the nonspecific nature of the symptoms, physicians tended to look for easily explainable causes such as recurrent viral illnesses. Many parents reported receiving simple explanations from their physicians that later turned out to be misdiagnoses (Fig. 1b). Worsening patterns of illness over time increased parents' anxiety, and

A

"He'd have these strange illnesses and we didn't think anything of it."

B

"The pediatrician told me it was a virus, and I thought, 'okay, kids get viruses'."

C

"I had ... other kids. ... and I knew something was wrong.

It wasn't no regular virus fever, like they were telling me.

I would spend every weekend and every waking moment and stay up all night long looking on line for what it would be. It was crazy, it really was. I have to pat myself on the back, I was working so hard to figure it out and eventually I found it. I knew it was Hyper IgD... Then I took it to the doctor and he thought I was crazy. But, I knew it."

D

"She was in the hospital with a $106^{\circ} \mathrm{F}\left(41.1^{\circ} \mathrm{C}\right)$ fever and her kidneys shut down. I knew that this wasn't normal."

Fig. 1 Quotes from parents of children with AIDs on difficulties experienced prior to receiving a diagnosis. Parent perceptions included: a Their child had an intermittent illness; $\mathbf{b}$ They were given simple explanations from doctors that were misdiagnoses; $\mathbf{c}$ They suffered from increased anxiety with worsening of their child's illness; $\mathbf{d}$ They struggled to find answers. AIDs, autoinflammatory diseases 
they became increasingly fearful and confused. Figure 1c provides an example of one such parent who stopped accepting her pediatrician's explanations and began looking for her own answers to her child's symptoms. First-time parents indicated that they had an especially difficult time recognizing that their child's symptoms could be more than a common viral illness. Most parents (86\%) reported that they only realized that something was seriously wrong with the health of their child after a severe medical emergency and/or hospitalization (Fig. 1d). Furthermore, many patients and their parents reported that they held on to their memories of what life was like before the onset of symptoms and mourned their subsequent loss of "normalcy."

Difficulties in establishing the diagnosis of AIDs

Parents encountered medical "merry-go-rounds" involving many specialist visits and diagnostic tests (Fig. 2a). For many, the diagnostic path included several specialist visits, long wait times for appointments, extensive testing, and misdiagnoses including Lyme disease, meningitis, H1N1 influenza, systemic lupus erythematosus, systemic juvenile idiopathic arthritis, atypical Kawasaki's disease, leukemia, lymphoma, bone cancer, and Crohn's disease. The most common misdiagnoses by general pediatricians included common cold, food allergy, hay fever, and varicella. Payors and health plans for several patients limited specialist visits, explaining that fevers are not notable causes of long-term damage, as well as the absence of confirmed diagnoses. Most parents (92\%) reported losing confidence in the healthcare system's ability to find an answer to their child's symptoms, while they also struggled with unsupportive school personnel and dismissive friends and relatives. Many parents stated that they lost self-confidence and began doubting their own judgment as it pertained to their child's health (Fig. 2b). The feeling of lost confidence was further

A

"The medical system was like a merry-go-round, endless doctors and tests and drugs but absolutely no resolution."

B

"My husband started to tell me I was imagining things. Others told me not to project my crazy on him."

"...Many times you begin to even doubt yourself and wonder if this is all in your head. Sometimes you wonder if you had something that would never be diagnosed, or would only be diagnosed during an autopsy. Heck, sometimes you wondered if you would ever know a day without pain...."

"I had to fight for the diagnosis. I know that sounds insane, and when I think about it, well yeah. It was insane. ... And they were telling me I was crazy. It went on like that for years, and I kept going to different hospitals. I couldn't get anyone ... to believe me."

C

"Without an advocate, I would never have gotten him the diagnosis."

"After we got the diagnosis, I could look at people and say, 'see, I'm not crazy!'”

Fig. 2 Quotes from parents of children with AIDs on the difficulties experienced during diagnosis. Challenges experienced during diagnosis included: a Parents encounter the medical "merry-go-round"; b Parents encounter unsympathetic voices on the path to diagnosis; c Families required a physician advocate to get their child diagnosed. AIDs, autoinflammatory diseases 
compounded by frustrations caused by an arduous and inconclusive diagnostic process. Many parents (generally mothers) began to question their own mental health and wondered if the symptoms were indeed real or if they were imagining things. As shown in Fig. 2c, some parents had to become their own advocate, and most parents felt that a physician advocate (a particularly engaged and proactive pediatrician, pediatric nurse, or pediatric rheumatologist) helped them to arrive at a diagnosis.

\section{The emotional impact of AIDs on children and their families}

While an accurate diagnosis provided vindication and relief, parents reported that it also led to further unanswered questions (Fig. 3a). Figure 3b shows that some parents had difficulties explaining the disease to their children in an age-appropriate manner. Some children with AIDs drew monsters when asked to depict how they felt about their disease (Fig. 3c, d).

Children with AIDs and their families experienced isolation (Fig. 3e). Parents reported that they remained hypervigilant (Fig. 3f) regarding their child's health and lived in constant anticipation of the next flare, irrespective of the success of their current therapy. Parents perceived the next flare as being "always around the corner."

\section{Parents' and patients' experiences of daily symptoms}

Many patients (64\%) reported the presence of disease symptoms between flares (Fig. 4a) despite receiving medications. These included myalgias, lymphadenopathy, aphthous ulcers, fatigue, and gastrointestinal symptoms. Daily symptoms persisted in some patients irrespective of flares and independent of fevers. Parents expressed little hope of improving these daily symptoms and reported that they were frustrated with physicians' inability to acknowledge symptoms between disease flares, which the parents considered to be related to the disease. Also, children with AIDs continued to suffer from common childhood illnesses, and many parents struggled to differentiate these from AID flares (Fig. 4b). Parents also commented that physicians in the emergency department, primary care providers, and other specialists also struggled to assess the condition of their children. Many parents developed an aversion to seeking medical care from providers who lacked education around AIDs and their management.

\section{Uncertainty post-diagnosis}

Parents reported the need to coordinate the process of care between their child's pediatrician, specialists, school nurses, and others (Fig. 5). After diagnosis, many parents concluded that the feelings of uncertainty was a

\section{A}

"I thought that the diagnosis would bring us some closure, but in a way diagnosis is where the real story started."

"...I was somewhat relieved to have an answer, a direction... But here we are with nearly as many questions as before..."

B

"How are you supposed to explain this to your child when you don't understand it yourself?"

C

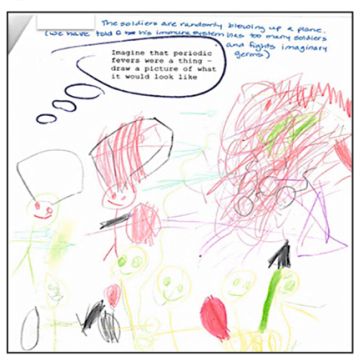

$\mathbf{E}$

"The hardest part is isolation. I'm 28 years old and I just haven't had the same experiences as my peers."

$\mathbf{F}$

"I am always aware, always conscious, always looking for that next flare waiting around the corner."

".. I try to 'fly under the radar' as I monitor his health I don't want him to feel sick. A hug is not always just a hug...it's also a thermometer!"

Fig. 3 Quotes from parents of children and drawing from patients with AIDs on emotional aspects. Emotional impact on the patients and their parents included: a After diagnosis, several questions remained unanswered from the parents' perspective; $\mathbf{b}$ Parents had difficulty in explaining the disease to their children; $\mathbf{c}$ Patient's perception of their mother's explanation of HIDS: "Soldiers in your body fight imaginary germs;" $\mathbf{d}$ Drawings by patients with AIDs in response to how they perceive their disease; e Children with AIDs and their families experienced overwhelming isolation; $\mathbf{f}$ Parents remained hypervigilant about their child's health. HIDS,

hyperimmunoglobulin D syndrome; AIDs, autoinflammatory diseases

hallmark of AIDs, which was one of the most emotionally challenging factors for them and their children (Fig. 6).

\section{Discussion}

In this study, we analyzed interview reports and written and video diaries from 12 families of patients with AIDs to understand their experiences from the onset of symptoms to diagnosis and treatment. The present qualitative analysis demonstrated that the burden of AIDs is considerable, and impacts the physical, social, and emotional aspects of patients and their families. AIDs are often misdiagnosed, leading to unnecessary hospitalizations 
A

"I don't know anyone (in our patient group) online who is
symptom free. I just don't think that happens."
"We'd like for more research to be done on all the symptoms
of [periodic fever]. Research focuses only on the flares but
doesn't look at what happens between flares. We don't feel
it's ever $100 \%$ gone between flares."

B

"I've learned to tell HIDS flares from the flu, but that took quite a while."

"How do you draw boundaries about what is and isn't FMF? I throw everything into the pot now. I feel like I am a cancer sniffing dog, I am hypervigilant now and I try not to overreact, but I am also monitoring him every minute of every day. I don't know how his FMF [symptoms] could change and that means that everything that happens to him could be FMF."

Fig. 4 Quotes from parents of children and patients with AIDs on the difficulties experienced post-diagnosis. Difficulties encountered by parents and patients included: a Some patients experienced daily symptoms; b Parents struggled to differentiate routine childhood illnesses from AIDs. FMF, familial Mediterranean fever; HIDS, hyperimmunoglobulin D syndrome; AIDs, autoinflammatory diseases

and therapeutic procedures [7-9]. In our study, we observed that patients with AIDs encountered a notable delay in the time to diagnosis that led to considerable stress and confusion for patients and their families.
One of the most difficult aspects expressed by parents of children with AIDs was the loss of what they considered a "normal" life, and this realization was the core tragedy for several families. Parents also reported feeling a loss of self-confidence with increasing alienation in the face of
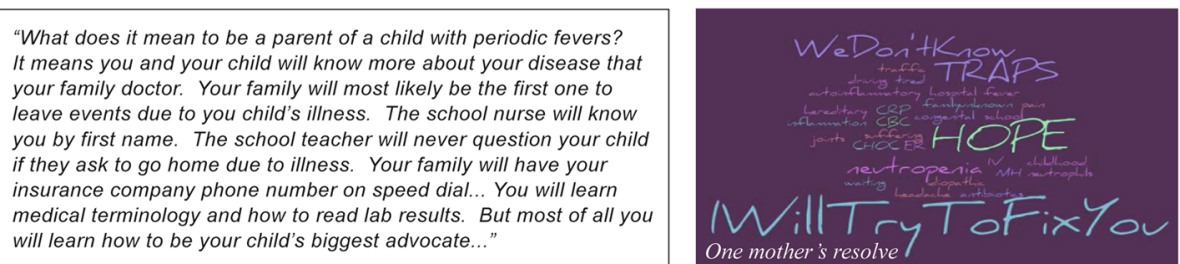

"The advice is easy don't ever give up. It takes years to even get a diagnosis, and then you have to contend with treatment (or lack thereof). Don't ever stop pursuing either. Listen to your gut. My gut has served me more as a mother than any book or article or doctor ever has. I continue to search for answers, for treatments to improve my son's life, and I will never stop. I've had so many doctors tell me that I was over reacting. One suggested l'd be torturing my son to subject him to weekly shots of Neupogen, the medication that ended up saving his life a year later. What if I had listened? Educate yourself. When the internet failed me (as it often does for rare diseases), I purchased a hematology textbook used by medical students. I borrowed medical text books from his doctors. I started scouring used book stores for affordable text books on hematology and rheumatology. I took free on-line biology classes offered by MIT. I did all of this to understand the nuts and bolts of what we were dealing with. To understand neutropenia and TRAPS, I had to first understand the body and where everything was going wrong. I was shocked at what was involved with the makings of a fever. How neutrophils and TNF receptors are involved with each other. How maybe these two diseases, which many doctors say are not related, just might have something to do with each other.

What I have learned from this experience is that despite how good your doctors are, they don't know you or your child like you do. Find doctors that you trust. Help them and be a team player, an informed one. Learn the basics so that you can have an intelligent discussion. Do not let these diseases just "happen" to you or your child. Do not take lying down. Stand up and fight. This will show your child that nothing will stop them from leading a normal life."

Fig. 5 Quotes from mothers of children with AIDs on the responsibilities taken for their child's care. AIDs, autoinflammatory diseases 
What is the hardest part about caring for a child with periodic fevers?

\begin{tabular}{|l|}
\hline "The hardest part about this disease is the difficulty in \\
predicting what my day is going to look like. I can set all the \\
plans in the world, but this disease can steal it all away. \\
I 'd love to spend every day like my best days, but for all \\
I know I 'm going to start crashing at $10 A M$ with joint pain, \\
fevers, etc. I may need to travel, or may be I want to go out \\
that night with friends. I will always push myself to do what \\
I can, but I 've canceled a lot of night plans. This impacts \\
me socially, it ostracizes me (impacting me psychologically) \\
and then there's the physical impacts. May be I need to be \\
at $100 \%$ because my job depends on it. May be I need to go \\
to 3 days of 12 hour meetings I don't have time for my \\
temperature to start spiking. This can also result in severe \\
anxiety which spreads to everything from weight control, to \\
OCD, to social anxiety." TRAPS patient, age 28
\end{tabular}

"The uncertainty. Not knowing what each day is going to bring. We have good weeks, months. Sometimes its just days. There is a thought that is always buzzing in the background of my brain, that this could all get worse. Or stay the same, or maybe get better"

Fig. 6 Quotes from children with AIDs and their parents on the uncertainty that pervades their lives. AIDs, autoinflammatory diseases

criticism and disbelief. Such experiences led to distrust in medical establishments, which persisted even after diagnosis.

A definitive diagnosis of AIDs provided vindication and relief, as well as an impetus to focus on further education and treatment options, yet it still took several parents a long time to trust the healthcare system again. Reports of distress and confusion during the diagnostic process have been documented in many families with children suffering from other disorders, including congenital heart defects and cleft palate $[10,11]$. In this study, uncertainty was reported as a cornerstone of life with AIDs. Uncertainities about the diagnosis and its implications led familiies to seek for online support and community.

Healthcare providers should be aware of the impact of the prolonged diagnostic journey on families and work to create an environment of trust where families and clinical staff can work collaboratively.

These findings should be interpreted in light of the qualitative nature of the study and the small sample size. All patients were from the United States, and so our findings may not reflect the diagnostic experience of patients with AIDs from other countries.

\section{Conclusions}

Our work highlights the need for an efficient and timely diagnosis of AIDs. Because the field of autoinflammation is relatively new and the diseases are rare, it is important to educate primary care providers to recognize these diseases among the many that cause frequent fevers. Providers should learn how to conduct the initial workup and when to refer patients with suspected AIDs to rheumatologists experienced in diagnosing and managing these rare syndromes [1]. Autoinflammatory Disease Clinics are being established as referral centers for this purpose. For patients and their families, patient support networks provide emotional support, advice in managing the medical and psychosocial aspects of AIDs, as well as tools to help prepare families for the future (a list of useful resources for patients and medical professionals are found in the Additional file 1). Treatment strategies also need to offer consistent and comprehensive patient education and support for patients and their families. Research to expedite diagnosis (such as with the use of wearable thermometers) and to enhance the recognition and treatment of daily symptoms that patients experience, could significantly improve the lives of patients with AIDs and their families. 


\section{Additional file}

Additional file 1: Interview Guide and Resources for Patients and Medical Professionals. (DOCX $44 \mathrm{~kb}$ )

\section{Abbreviations}

AIDs: Autoinflammatory diseases; FMF: Familial Mediterranean fever; MKD/ HIDS: Mevalonate kinase deficiency/hyperimmunoglobulin D syndrome; TNF: Tumor necrosis factor; TRAPS: Tumor necrosis factor receptor-associated periodic syndrome

\section{Acknowledgments}

We thank the families that participated in the study and Christina Grabiec for initiating the research concept. Medical writing support was provided by Divya Chandrasekhar, PhD of Novartis Healthcare Pvt. Ltd., Hyderabad, India, which was funded by Novartis Pharmaceuticals Corporation in accordance with Good Publication Practice (GPP3) guidelines (http://www.ismpp.org/gpp3).

\section{Funding}

This research was funded by Novartis Pharmaceuticals Corporation, New Jersey, United States. Families received an honorarium for their participation.

\section{Availability of data and materials}

The data supporting the conclusions of this article are included within the article.

\section{Authors' contributions}

JSH participated in analysis verification and provided feedback on the manuscript; KGL participated in analysis verification and provided feedback on the manuscript; AS participated in data collection, qualitative analysis, final analysis, and provided feedback on the manuscript; KD participated in analysis verification and provided feedback on the manuscript. All authors read and approved the final manuscript.

\section{Ethics approval and consent to participate}

This was a market research study and therefore ethics committee approval was not obtained. Patients signed a standard market research consent form.

\section{Consent for publication}

Not applicable.

\section{Competing interests}

- $\quad J S H$ received personal fees from Novartis outside the submitted work

- KGL is an employee of Novartis Pharmaceuticals Corporation

- AS received personal fees from Novartis

- KD reports non-financial support and other from Novartis Pharmaceuticals Inc., other from Flince Research Inc. during the conduct of the study, and grants from Swedish Orphan Biovitrum (SOBI) outside the submitted work

\section{Publisher's Note}

Springer Nature remains neutral with regard to jurisdictional claims in published maps and institutional affiliations.

\section{Author details}

${ }^{1}$ Boston Children's Hospital, Boston, MA 02115, USA. ${ }^{2}$ Beth Israel Deaconess Medical Center, Boston, MA 02215, USA. ${ }^{3}$ Novartis Pharmaceuticals Corporation, East Hanover, NJ, USA. ${ }^{4}$ Flince Research, Brooklyn, NY, USA.

${ }^{5}$ Autoinflammatory Alliance, San Francisco, CA, USA.

Received: 27 February 2018 Accepted: 29 August 2018

Published online: 06 September 2018

\section{References}

1. Hausmann JS, Dedeoglu F. Autoinflammatory diseases in pediatrics. Dermatol Clin. 2013:31:481-94.

2. Federici S, Sormani MP, Ozen S, Lachmann HJ, Amaryan G, Woo P, KonéPaut I, Dewarrat N, Cantarini L, Insalaco A, Uziel Y, Rigante D, Quartier P, Demirkaya E, Herlin T, Meini A, Fabio G, Kallinich T, Martino S, Butbul AY,
Olivieri A, Kuemmerle-Deschner J, Neven B, Simon A, Ozdogan H, Touitou I, Frenkel J, Hofer M, Martini A, Ruperto N, Gattorno M. Paediatric rheumatology international trials organisation (PRINTO) and Eurofever project. Evidence-based provisional clinical classification criteria for autoinflammatory periodic fevers. Ann Rheum Dis. 2015;74:799-805.

3. van der Hilst JC, Bodar EJ, Barron KS, Frenkel J, Drenth JP, van der Meer JW, Simon A. International HIDS study group. Long-tem follow-up, clinical features, and quality of life in a series of 103 patients with hyperimmunoglobulinemia D syndrome. Medicine (Baltimore). 2008;87:301-10.

4. Lainka E, Bielak M, Lohse P, Timmann C, Stojanov S, von Kries R, Niehues T, Neudorf U. Familial Mediterranean fever in Germany: epidemiological, clinical, and genetic characteristics of a pediatric population. Eur J Pediatr. 2012;171:1775-85.

5. Migita K, Uehara R, Nakamura Y, Yasunami M, Tsuchiya-Suzuki A, Yazaki M, Nakamura A, Masumoto J, Yachie A, Furukawa H, Ishibashi H, Ida H, Yamazaki K, Kawakami A, Agematsu K. Familial Mediterranean fever in Japan. Medicine (Baltimore). 2012;91:337-43.

6. Toplak N, Frenkel J, Ozen S, Lachmann HJ, Woo P, Koné-Paut I, De Benedetti F, Neven B, Hofer M, Dolezalova P, Kümmerle-Deschner J, Touitou I, Hentgen V, Simon A, Girschick H, Rose C, Wouters C, Vesely R, Arostegui J, Stojanov S, Ozgodan H, Martini A, Ruperto N, Gattorno M. Paediatric rheumatology international trials organisation (PRINTO), Eurotraps and Eurofever projects. An international registry on autoinflammatory diseases: the Eurofever experience. Ann Rheum Dis. 2012;71:1177-82.

7. Berody S, Galeotti C, Koné-Paut I, Piram M. A restrospective survey of patients's journey before the diagnosis of mevalonate kinase deficiency. Joint Bone Spine. 2015:82:240-4.

8. Ben-Chetrit E, Touitou I. A patient with periodic fever syndrome: a 20-year delay in diagnosis. Scand J Rheumatol. 2009:38:71-3.

9. Grouteau E, Chaix Y, Graber D, Breton A, Claeyssens S, Kuhlein E, Carrière JP. Pseudo-periodic disease with hyperimmunoglobulinemia D: a never-ending story with probable prenatal onset. Arch Pediatr. 1998;5:280-4.

10. Nelson PA, Kirk SA, Caress AL, Glenny AM. Parents' emotional and social experiences of caring for a child through cleft treatment. Qual Health Res. 2012;22:346-59

11. McKechnie AC, Pridham K. Preparing heart and mind following prenatal diagnosis of complex congenital heart defect. Qual Health Res. 2012;22: 1694-706.

\section{Ready to submit your research? Choose BMC and benefit from:}

- fast, convenient online submission

- thorough peer review by experienced researchers in your field

- rapid publication on acceptance

- support for research data, including large and complex data types

- gold Open Access which fosters wider collaboration and increased citations

- maximum visibility for your research: over $100 \mathrm{M}$ website views per year

At $\mathrm{BMC}$, research is always in progress.

Learn more biomedcentral.com/submissions 